\title{
Psychological significance of the irritable colon syndrome
}

\author{
I. G. HISLOP
}

From the Gastroenterology Unit, The Queen Elizabeth Hospital, Woodville, South Australia

SUMMARY Sixty-seven patients with the irritable colon syndrome are reported. The symptom complex is considered to be a concomitant of an affective disorder, and the psychological factors associated with the genesis of the illness are discussed. Fifty-six patients received treatment with anti-depressant therapy, of whom $80 \%$ reported significant improvement.

Although the irritable colon syndrome has been considered to result from emotional stress (Ryle, 1928; White and Jones, 1940; Lumsden, Chaudhary, and Truelove, 1963), its significance in terms of psychological dysfunction has not been defined. Fatigue, loss of concentration, depression, or anxiety were noted in the majority of the 130 cases studied by Chaudhary and Truelove (1962), and they concluded that psychological factors were preeminent in the genesis of the condition. Heffernon and Lippincott (1966) have reported that psychotic depression may be masked by the irritable colon syndrome, and Dorfman (1967) has suggested that spastic colon may be a symptom of depression.

This paper reviews the symptomatology of the jrritable colon syndrome, and presents evidence that the abdominal symptom complex is a psychophysiological concomitant of an affective disorder.

\section{Patients and Methods}

Sixty-seven patients with the irritable colon syndrome were seen either in private practice or in an outpatient gastroenterology clinic of a general hospital during the eight months from September 1968 to April 1969. The diagnosis was established by the occurrence of abdominal pain, constipation and/or diarrhoea, in the absence of demonstrable organic disease. In each patient, a complete blood picture, erythrocyte sedimentation rate, sigmoidoscopic examination, and barium enema were performed. Radiographic examinations of the upper gastrointestinal tract and gallbladder were carried out where indicated. In each patient with diarrhoea a stool culture was performed, and several had a 72-hour faecal fat

Received for publication 7 April 1971. estimation. Patients with coexisting gastrointestinal disease were excluded from this study. A control group of 67 subjects, age- and sex-matched with the patients, was selected from hospital visitors and patients attending the Casualty Department for minor injury. Persons with abdominal pain or dyspeptic symptoms were excluded from this group. The purpose of the control group was to assess the prevalence of psychological symptoms and stress factors amongst a comparable group of normal subjects.

\section{Results}

AGE AND SEX

The series comprised 47 females and 20 males, a sex ratio of $2.4: 1$. In both sexes, diagnosis of the condition was unusual below the age of 20 years and over the age of 60 years. In males, the commonest age group at diagnosis was the fifth decade, whereas in females there was an even distribution between the ages of 30 to 60 years (Fig. 1).

\section{DURATION OF SYMPTOMS}

Longevity of symptoms before diagnosis was a feature of the illness. The disorder had been present less than six months in 19 patients, and for more than two years in 38, 22 of whom reported symptoms exceeding five years. During this time, many patients had sought medical attention and had been given a variety of medications, including antacids and anticholinergics, without significant relief. None had received antidepressant therapy. Nineteen patients had undergone abdominal surgery, appendicectomy (eight patients) and cholecystectomy (five patients) being the two commonest operations performed. 


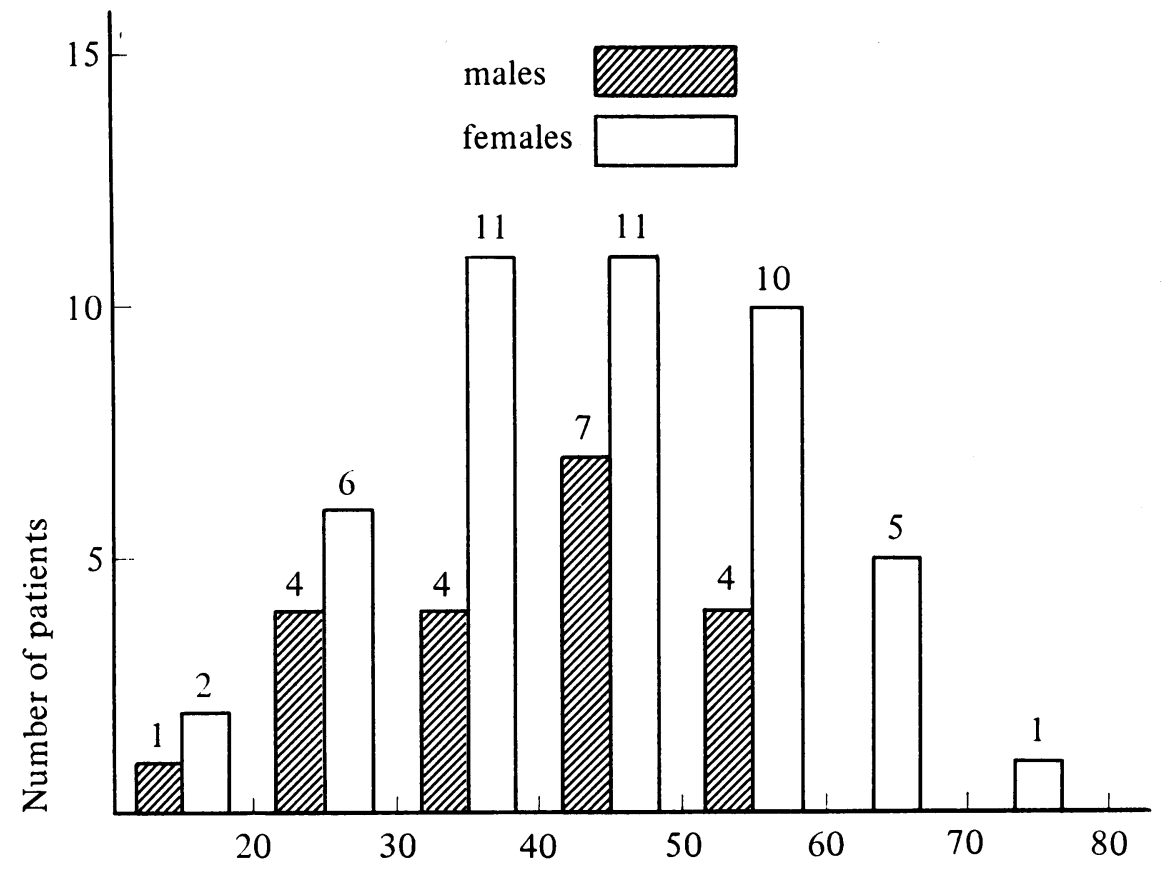

Fig. 1. Age of patient at diagnosis.

Age of patients in years

ABDOMINAL PAIN

Sixty-four patients experienced abdominal pain which was usually sited over the distribution of the colon (Fig. 2). The intensity of pain varied considerably, was commonly severe, and often lasted for several hours. Fifty-two patients reported upper abdominal pain, but five had associated lower abdominal pain. Two patients had central pain and 10 had pain only in the lower abdomen. In all but eight instances upper abdominal pain was continuous, whereas lower abdominal pain was generally noted to be colicky. In half the patients, pain radiated into the back. Several patients reported that the site of pain varied over an interval of time. Nocturnal pain occurred in 32 patients. Abdominal tenderness, usually over the site of the pain, was elicited in 42 patients.

RELATION OF PAIN TO GASTROINTESTINAL FUNCTION

In 31 patients, pain occurred 10 to 30 minutes after food, often resulting in a lack of desire to eat because of its severity. Abdominal distension after meals was a prominent symptom in 25 patients. Thirty-four persons were relieved of pain after defaecation or the passage of flatus; in 10 others the pain initiated an urge to stool. Pain was often exacerbated with increasing constipation, and partial

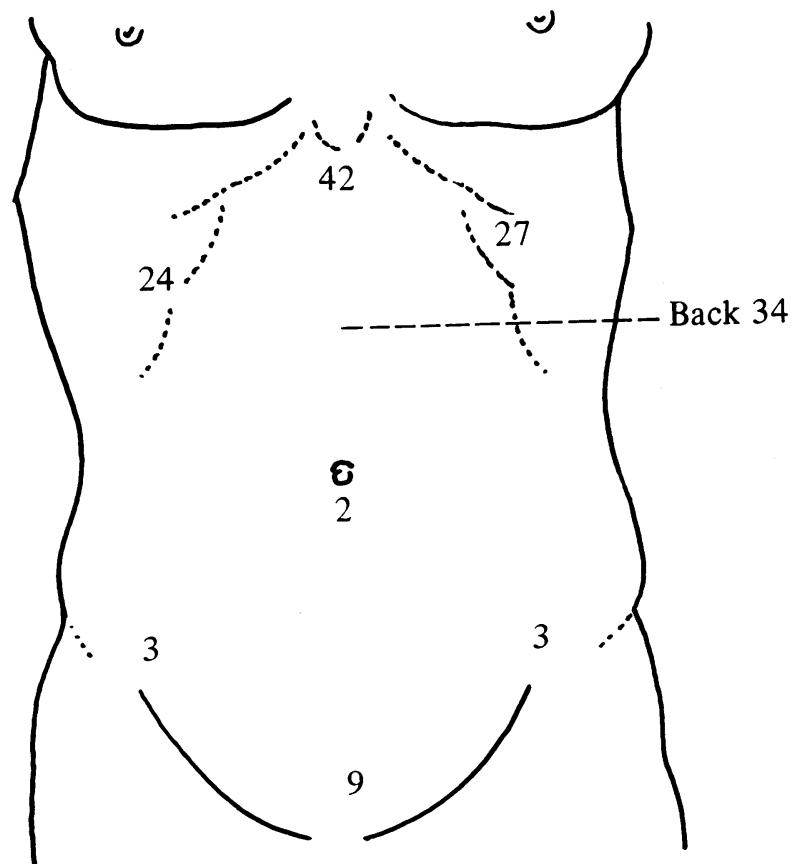

Fig. 2. Distribution of abdominal pain. Diagram represents frequency with which each site was affected; in many patients more than one area was involved. 
relief was obtained by the use of a hydrophilic gel compound. In contrast, purgation tended to aggravate the pain. Vomiting was reported by 29 patients and was initiated by pain in 20 . Nineteen others noted persistent nausea, in the absence of vomiting.

\section{BOWEL HABIT}

Twenty-nine patients had constipation, six had alternating bouts of diarrhoea and constipation, and 24 had diarrhoea which was either continual or occurred in bouts (Table I). Patients often experienced a characteristic early morning exacerbation of diarrhoea, but nocturnal episodes were not uncommon. Postprandial urgency of defaecation was frequently described, and certain dietary factors were often incriminated, particularly fried foods, fresh fruit, and alcohol. Eight patients denied any abnormality in bowel habit.

\begin{tabular}{lc}
\hline Bowel Function & Patients \\
\hline Normal & 8 \\
Constipation & $29^{1}$ \\
Diarrhoea & 24 \\
Alternating constipation and diarrhoea & 6 \\
\hline
\end{tabular}

Table I Change in bowel habit

${ }^{1}$ Many patients with constipation suffered spurious diarrhoea as a result of persistent purgation.

\section{DOMESTIC STRESS}

Dysharmony between husband and wife or problems of relationships between the patient and other close relatives were found to occur in 26 patients and 15 controls (Table II). Thirteen patients ( 12 females and one male) and five of the control group were divorced or separated. Domestic discord was reported by 23 of 42 married female patients and three of 16 married males.

\begin{tabular}{lll}
\hline & Patients & Controls \\
\hline Marital & 26 & 15 \\
Financial & 12 & 11 \\
Childhood & 28 & 21 \\
\hline
\end{tabular}

Table II Stress factors

FINANCIAL AND OCCUPATIONAL STRESS

Twelve patients (10 females and two males) and 11 controls (nine females and two males) considered economic difficulties or occupational tension to represent significant stress in their lives.

\section{CHILDHOOD STRESS}

Twenty-eight patients and 21 controls described an emotionally disturbed childhood. The commonest reasons given were parental separation, loss of a parent in early childhood, inadequate stepparents or guardians, or poor family relationships. There were five patients who had as children suffered recurrent physical punishment inflicted by an intoxicated parent. None of the control group reported such severe trauma.

\section{SYMPTOMS OF ALTERED AFFECT}

Concomitant symptoms of an affective disorder were assessed, and included fatigue, lowering of mood (subjective depression), weeping, and disturbances in sleep and appetite (Table III). These symptoms occurred with greater frequency in females than in males and were more common in patients than in controls. Depression was reported by the majority of females (41 patients) but was present in only eight males. Twelve of the control subjects suffered periods of depression. Fifteen patients (two males and 13 females) were judged to be suicidal, and five admitted past suicidal attempts. Two control subjects were considered suicidal. Fatigue was the commonest symptom reported, and was prominent in 60 patients ( 16 males and 44 females) but only in 11 controls. Insomnia, characteristically of the early morning awakening type, occurred in 54 patients and in 18 of the control group. Other symptoms of an affective disorder were frequently described, and included diurnal variation of symptoms, loss of interest in social environment, feelings of inadequacy, and loss of libido. Anxiety symptoms, consisting of palpitations, dizziness, tremor, or sweating, were noted by 46 patients and 15 controls. Fear of serious disease, particularly carcinoma, was expressed by many patients, and more than half noted exacerbation of their symptoms under conditions of stress, generally related to periods of anxiety.

\begin{tabular}{lll}
\hline Symptom & Patients & Controls \\
\hline Fatigue & 60 & 11 \\
Depression & 49 & 12 \\
Insomnia & 54 & 18 \\
Weeping & 42 & 8 \\
Anorexia & 60 & 13 \\
Suicidal & 15 & 2 \\
\hline
\end{tabular}

Table III Symptoms of altered affect

\section{SIGNIFICANT EPISODES OF STRESS}

An acute episode of psychological stress signifying psychic 'loss' or 'threat' occurred before the onset of symptoms in 34 patients. This included death or severe illness in a close relative (nine patients), surgery (five), marital dysharmony resulting in trauma or separation (four), 'migration' from close 
family (four), injury or illness (three), pregnancy (two), birth of defective infant (two), others (five). In most of these situations an element of personal responsibility, self blame, or guilt was apparent.

\section{Treatment}

Sixty-five patients were treated with either a phenothiazine (trifluoperazine) or a tricyclic antidepressant (amitriptyline). A hydrophylic gel for the treatment of constipation was the only other therapy prescribed. Nineteen patients received phenothiazine therapy: five reported symptomatic improvement in abdominal and affective symptoms, four sustained complete relief, and 10 responded poorly. Antidepressant therapy was administered in 56 patients. Twenty-nine became symptom free, 16 showed definite improvement, and 11 reported no benefit. Of the 11 failures, four patients had discontinued treatment because of side effects from the drug-notably drowsiness or a dry mouth. The 56 patients who received amitriptyline included nine of the 10 patients who did not benefit from a phenothiazine: five became asymptomatic and two others reported a good result. One patient who responded poorly to the antidepressant obtained a satisfactory response from trifluoperazine.

\section{Discussion}

Kline (1964) listed the five symptoms most commonly associated with depression as a feeling of sadness, fatigue, loss of interest in social environment, self neglect, and insomnia. Gallemore and Wilson (1969) refer more specifically to disturbances in sleep, appetite, sex and psychomotor activity as concomitants of an abnormal affect. Depressed patients may present with somatic symptoms as their chief complaint (Rosenthall, 1968), and frequently the depression may be obscured by the psychosomatic disorder (Waggoner, 1961; Lesse, 1968). Such somatic symptoms are especially referable to the gastrointestinal tract and include abdominal pain, nausea, vomiting, and constipation (Feldman, 1965). Although some workers (Chaudhary and Truelove, 1962; Heffernon and Lippincott, 1966; Hill and Blendis, 1967) have reported an associated depressive state in some patients with the irritable colon syndrome, others (Diamond, 1964; Dorfman, 1967) have considered the disorder to result from a depressive illness.

In the present study disturbances in activity (fatigue), sleep (insomnia), mood (depression and weeping), and appetite (anorexia) were considered to represent the setting of an affective disorder. Depression was described by 49 of the 67 patients, but the remainder denied any significant alteration in mood. Nevertheless, symptoms of an affective disorder were absent in only three patients in the entire series. Psychogenic abdominal pain occurred in 64 patients, and in each instance the diagnosis was supported by the exclusion of organic disease by appropriate investigation.

Merskey (1968) has outlined three mechanisms for the production of psychogenic pain: delusional, due to conversion hysteria, or associated with muscle tension. Walters (1961) considers spastic colon to be an example of psychogenic pain resulting from muscle tension. Stengel (1965) and Gallemore and Wilson (1969) regard psychogenic pain as a concomitant symptom of an affective disorder, but others (Wilson and Hohman, 1966; Gallemore and Wilson, 1969) believe pain to be an affect in its own right. It has been further emphasized by Wilson and Nashold (1970) that, although depression is the commonest affective disorder associated with psychogenic pain, patients may in some instances have a primary complaint of pain. Experimental evidence has substantiated a muscular component in the irritable colon syndrome. An alteration in the motility of the large and small bowel has been shown to occur in association with the pain (Connell, Avery Jones, and Rowlands, 1965; Holdstock, Misiewicz, and Waller, 1969), and with the diarrhoea and constipation (Wangel and Deller, 1965; Chaudhary and Truelove, 1961 ; Bloom, LoPresti, and Farrar, 1968). Mediation of these changes has been reputed to occur via the autonomicnervous system (Heffernon and Lippincott 1966).

Chaudhary and Truelove (1962) have incriminated bowel infection as the aetiological agent in some patients with the irritable colon syndrome. In four cases in the present series the diarrhoea appeared to have been initiated by an infection, although no evidence was produced to confirm this. Two of these patients had persistent painless diarrhoea, while in the other two pain occurred as a mild symptom preceding defaecation. Symptoms of a disturbed affect were present in all four patients. It is postulated that infective diarrhoea occurring in a patient with a preexisting affective disorder, or with the potential to suffer such a psychological reaction, may persist as an irritable colon syndrome. The relative frequency of affective symptoms in the control group reflects the availability of such potential material in the population at large. Each of the four patients with diarrhoea of possible infective origin returned to normal following a short course of psychotropic drug therapy.

The significance of stress in the causation of this disorder has been recognized since its initial description by Bockus, Banks, and Wilkinson in 1928. 
However, there has been no identification of the significant psychological factors which may be incriminated in its evolution. It has been shown by comparison with the control group that financial problems and business worries were no more common in patients than in the normal population, and that although marital dysharmony was reported by 26 patients, it also occurred in 15 of the control subjects. Likewise, stress in childhood was present in 28 patients and in 21 of the control group. It is clear that comparisons of stress under these broad headings contribute little to the understanding of the psychopathological factors which may be involved.

Engel (1962) has outlined three categories of psychological stress, namely, 'object loss', 'threat of injury', or 'drive frustration'. He believes that translation into somatic complaints results from a failure to contain adequately psychological stress at the mental level. Guilt, conscious or subconscious, is considered an invariable factor in the choice of pain as a psychogenic symptom (Engel, 1958). In 34 subjects the pain had a definite onset and followed shortly after a 'loss' or 'threat' situation, in which a degree of self blame was often apparent. However, in half the patients there was no demonstrable event which could be identified in the precipitation of the illness. It is possible that the production of pain in these patients resulted from a different psychological mechanism. Many patients had a long history of intermittent pain dating from their adolescence, and the abdominal symptoms appeared to be part of a chronic affective disorder. Engel (1958) believes that such patients have a 'pain-prone' personality, in which pain represents a means of emotional expression. Amongst this group were five patients who suffered particularly severe emotional stress in their childhood, but in the majority no such history was available.

Anxiety symptoms were prominent in many of the patients. Stengel (1965) and Spear (1967) believe that anxiety is an important factor in the production of psychogenic pain. The potentiating affect of anxiety on pain has been pointed out by Engel (1967), and it is worthy of note that over half the patients noted exacerbation of their symptoms when they became tense or distressed. Allaying anxiety was found to be of particular importance in the management of the subjects with the irritable colon syndrome. Many feared the presence of organic disease, especially cancer, and satisfactory reassurance greatly reduced the severity of the symptoms in many instances. Explanation of the symptoms as a physiological reaction affecting bowel motility and function frequently contributed to the alleviation. The efficacy of antidepressant therapy in patients with the irritable colon syndrome has been reported previously by Kasich (1965) and Feldman (1965). Diamond (1964) noted a beneficial response in 48 of 51 patients so treated. Antidepressant therapy has also been considered the most appropriate treatment for psychogenic pain (Stengel, 1965; Spear, 1967). Because the irritable colon syndrome represents a physiological component of an affective disorder, treatment directed towards the alleviation of the psychological reaction appears to result in eradication of gastrointestinal symptoms in most cases. Eighty percent of patients receiving antidepressant therapy in this study reported benefit, ranging from moderate improvement to complete relief of symptoms. However, the average time of follow up in this series was only three months.

\section{References}

Bloom, A. A., LoPresti, P., and Farrar, J. T. (1968). Motility of the intact human colon. Gastroenterology, 54, 232-240.

Bockus, H. L., Bank, J., and Wilkinson, S. A. (1929). Neurogenic mucous colitis. Trans. Amer. gastroent. Ass., 31, $277-297$.

Chaudhary, N. A., and Truelove, S. C. (1961). Human colonic motility: a comparative study of normal subjects, patients with ulcerative colitis, and patients with the irritable colon syndrome. Gastroenterology, 40, 1-36.

Chaudhary, N. A., and Truelove, S. C. (1962). The irritable colon syndrome. Quart. J. Med., 31, 307-322.

Connell, A. M., Avery Jones, F., and Rowlands, E. N. (1965). Motility of the pelvic colon. Part IV Abdominal pain associated with colonic hypermotility after meals. Gut, 6, 105-112.

Diamond, S. (1964). Amitriptyline in the treatment of gastro-intestinal disorders. Psychosomatics, 5, 221-224.

Dorfman, W. (1967). Somatic components of depression. Psychosomatics, 8, 4-5.

Engel, G. L. (1958). Psychogenic pain. Med. Clin. N. Amer., 42, 1481-1492.

Engel, G. L. (1962). Psychological Development in Health and Disease, p. 331. Saunders, Philadeplphia.

Engel, G. L. (1967). The concept of psychosomatic disorder. $J$. psychosom. Res., 11, 3-9.

Feldman, P. E. (1965). The mask of depression. J. Kans. med. Soc., 66, 6-10.

Gallemore, J. L., Jr., and Wilson, W. P. (1969). The complaint of pain in the clinical setting of affective disorders. Sth. med. J. (Bgham, Ala), 62, 551-555.

Heffernon, E. W., and Lippincott, R. C. (1966). The gastrointestinal response to stress (the irritable colon). Med. Clin. N. Amer., 50, 591-595.

Hill, O. W., and Blendis, L. (1967). Physical and psychological evaluation of 'non-organic' abdominal pain. Gut, 8, 221-229.

Holdstock, D. J., Misiewicz, J. J., and Weller, S. L. (1969). Observations on the mechanism of abdominal pain. Gut, 10. 19-31.

Kasich, A. M. (1965). Management of emotional disorders, anxiety and depression in patients with gastrointestinal disease. Curr. ther. Res., 7, 542-547.

Kline, N. S. (1964). The practical management of depression. J. Amer. med. Ass., 190, 732-740.

Lesse, S. (1968). Masked depression-a diagnostic and therapeutic problem. Dis. nerv. Syst., 29, 169-173.

Lumsden, K., Chaudhary, N. A., and Truelove, S. C. (1963). The irritable colon syndrome. Clin. Radiol., 14, 54-63.

Merskey, H. (1968). Psychological aspects of pain. Postgrad. med. J., 44, 297-306.

Rosenthal, S. H. (1968). Recognition of depression. Geriatrics, 23, 111-115.

Ryle, J. A. (1928). An address on chronic spasmodic affections of the colon and the diseases which they simulate. Lancet, 2, 11151119.

Spear, F. G. (1967). Pain in psychiatric patients. J. psychosom. Res., 11, 187-193. 
Stengel, E. (1965). Pain and the psychiatrist. Brit. J. Psychiat., 111, 795-802.

Waggoner, R. W. (1961). Depression the simulator. Psychosomatics, 2, 264-266.

Walters, A. (1961). Psychogenic regional pain alias hysterical pain. Brain, 84, 1-18.

Wangel, A. G., and Deller, D. J. (1965). Intestinal motility in man. III. Mechanisms of constipation and diarrhea with particular reference to the irritable colon syndrome. Gastroerotenlogy, 48. 69-84.
White, B. V., and Jones, C. M. (1940). Mucous colitis: a delineation of the syndrome with certain observations on its mechanism and on the role of emotional tension as a precipitating factor, Ann. intern. Med., 14, 854-872.

Wilson, W. P., and Hohman, L. B. (1960). Varieties of affects and their frequency of occurrence in affective disorders. pp. 438-439 In Abstracts of Fourth World Congress of Psychiatry, Madrid (Excerpta Medica Foundation International Congress Series No. 117.)

Wilson, W. P., and Nashold, B. S., Jr. (1970). Pain and emotion. Postgrad. Med., 47, 183-187.

\section{The May 1971 Issue}

\section{THE MAY 1971 ISSUE CONTAINS THE FOLLOWING PAPERS}

An ultrastructural study of the effect of neomycin on the colon in the human subject and in the conventional and the germ-free mouse A. P. R.

Movement of segmental constrictions in the human colon JAMES A. RITCHIE

Absorption of sodium and water by human rectum measured by a dialysis method C. J. EDMONIDS

Experimental hepatic cirrhosis in dogs caused by chronic massive iron overload PEDRO EURICO LISBOA

Observations on iron in the jejunal lumen after a standard meal J. GLOVER AND A. JACOBS

Disappearance of gastrin and pentagastrin in the portal circulation JOHN M. TEMPERLEY, BRIAN $H$. STAGG, AND JOHN H. WYLLIE ALUWIHARE

A comparison of alcoholic pancreatitis in rat and man H. SARLES, G. LEBREUIL, F. TASSO, C. FIGARELLA, F. Clemente, M. A. DeVAUX, B. FAGONDE, AND H. PAYAN

The value of phenol red and chromic chloride as nonabsorbable gastric indicators R. J. CLARKE AND J. ALEXANDER WILLIAMS

Ganglion cell changes in experimental stenosis of the gut R. J. EARLAM

A paediatric tube and capsule for suction biopsy of the small intestinal mucosa designed for direct nasogastric intubation R. E. SCHNEIDER AND R. CHANG

Progress report Intestinal absorption in the "contaminated small-bowel syndrome' MICHAEL GRACEY

Progress report Sterol absorption-from lumen to liver NEIL MCINTYRE

\section{Notes and activities}

Copies are still available and may be obtained from the PUBLISHING MANAGER, BRITISI MEDICAL ASSOCIATION, TAVISTOCK SQUARE, LONDON, WC1H 9JR, price $87 \frac{1}{2} \mathrm{p}$ 